\title{
Isotopic tracing of thallium contamination in soils affected by emissions from coal-fired power plants
}

Aleš Vaněk ${ }^{1 *}$, Zuzana Grösslová ${ }^{1}$, Martin Mihaljevič², Jakub Trubač², Vojtěch Ettler², Leslaw Teper ${ }^{3}$, Jerzy Cabala ${ }^{3}$, Jan Rohovec ${ }^{4}$, Tereza Zádorová ${ }^{1}$, Vít Penížek ${ }^{1}$, Lenka Pavlů ${ }^{1}$, Ondřej Holubík ${ }^{1}$, Karel Němeček ${ }^{1}$, Jakub Houška ${ }^{1}$, Ondřej Drábek ${ }^{1}$, Christopher Ash $^{1}$

${ }^{1}$ Department of Soil Science and Soil Protection, Faculty of Agrobiology, Food and Natural Resources, Czech University of Life Sciences Prague, Kamýcká 129, 16521 Praha 6, Czech Republic

${ }^{2}$ Institute of Geochemistry, Mineralogy and Mineral Resources, Faculty of Science, Charles University in Prague, Albertov 6, 12843 Praha 2, Czech Republic

${ }^{3}$ Department of Economic Geology, Faculty of Earth Sciences, University of Silesia, Bedzinska 60, 41-200 Sosnowiec, Poland

${ }^{4}$ Institute of Geology of the CAS, v.v.i., Rozvojová 269, 16500 Praha 6, Czech Republic

*Corresponding author

Phone: +420 224382 752; Fax: +420 234381 836; E-mail: vaneka@af.czu.cz 


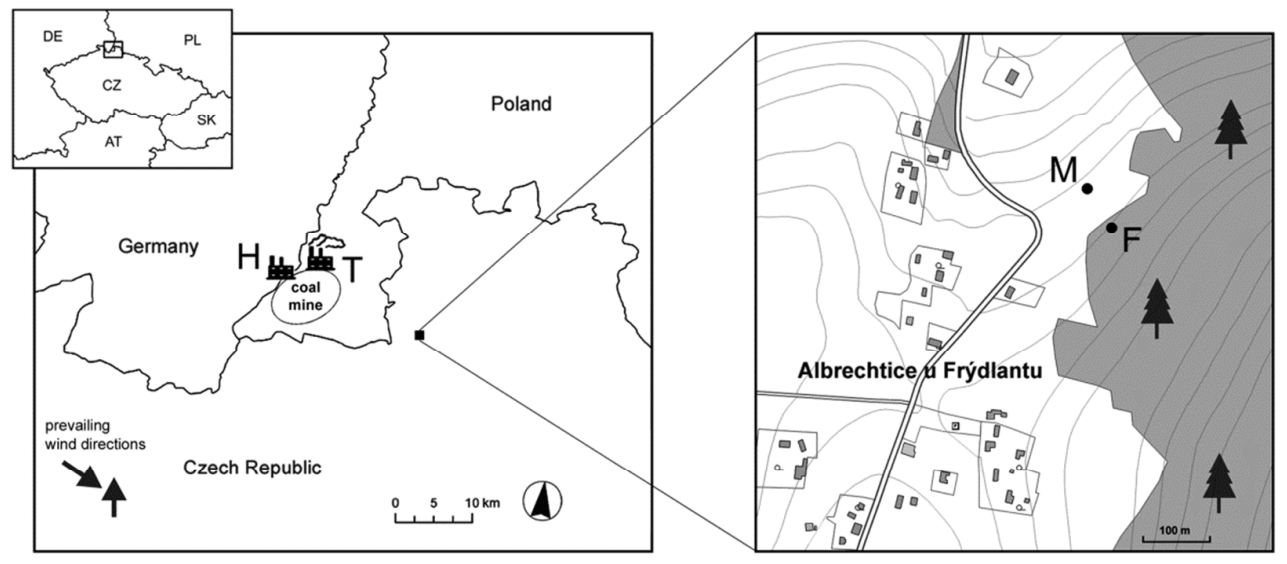

FIGURE S1. Location of the study area and the soil sampling sites; forest (F) and meadow (M) soil profiles; (T) "Turów" - the coal-fired power station (Poland); (H) "Hirschfelde" the former coal-fired power station (Germany). The GPS coordinates of soil profiles were as

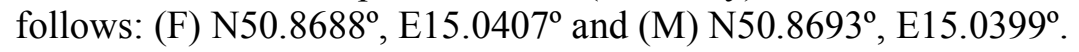

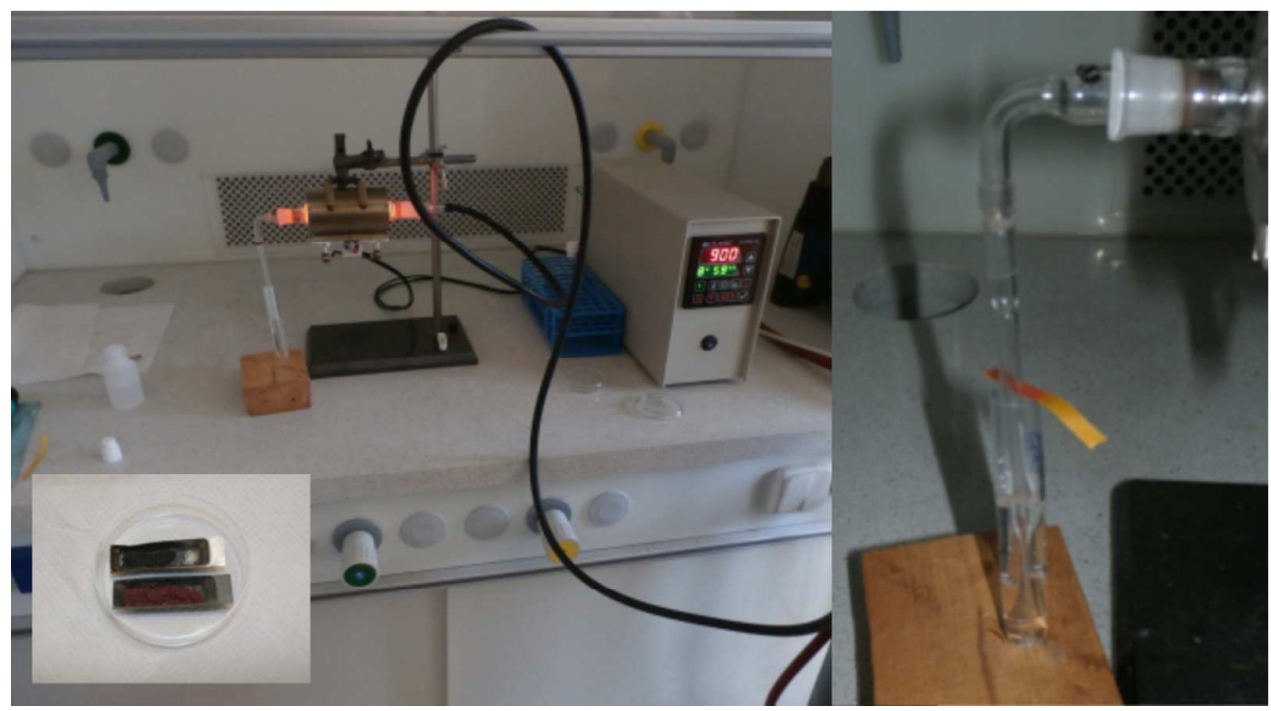

FIGURE S2. A model set-up, consisting of a quartz tube and a laboratory programmable induction oven followed by a glass bubbler $(0.1 \mathrm{M} \mathrm{HCl})$ in a synthetic air atmosphere, which was used for thermal (temperature-controlled) desorption of $\mathrm{Tl}$ from coal pyrite, simulating conditions for coal combustion in the CFB boiler. 
TABLE S1. Measured and certified Tl values for standard reference materials, NIST 2711 (Montana Soil) (National Institute of Standards and Technology, USA) and INCT-TL-1 (Tea Leaves) (Institute of Nuclear Chemistry and Technology, Poland). The analyses were carried out in triplicate and depict mean $\pm 1 \mathrm{SD}$. The recoveries calculated for $\mathrm{Tl}$ correspond to $95 \%$ and $97 \%$, respectively.

\begin{tabular}{|l|c|c|}
\hline & measured $(\mathrm{mg} / \mathrm{kg})$ & certified $(\mathrm{mg} / \mathrm{kg})$ \\
\hline NIST 2711 & $2.35 \pm 0.20$ & $2.47 \pm 0.15$ \\
\hline INCT-Tl-1 & $0.061 \pm 0.008$ & $0.063 \pm 0.005$ \\
\hline
\end{tabular}

TABLE S2. Measured and reference Tl concentration and T1 isotope data for USGS standard reference material, AGV-2 (Andesite).

\begin{tabular}{|l|c|c|c|c|c|c|c|}
\hline & $\mathrm{Tl}(\mu \mathrm{g} / \mathrm{kg})$ & $2 \mathrm{SD}$ & $\varepsilon^{205} \mathrm{Tl}$ & $2 \mathrm{SD}$ & $\mathrm{n}$ & dissolutions & reference \\
\hline AGV-2 & 245 & 32 & -3.4 & 0.7 & 6 & 6 & This study \\
\hline AGV-2 & 267 & 35 & -3 & 0.6 & 15 & 8 & 1 \\
\hline AGV-2 & & & -2.7 & 0.4 & 1 & 1 & ${ }^{2}$ \\
\hline AGV-2 & & & -1.9 & 0.5 & 1 & 1 & 3 \\
\hline
\end{tabular}

\section{REFERENCES}

(1) Prytulak, J.; Nielsen, S. G.; Plank, T.; Barker, M.; Elliot, T. Assessing the utility of thallium and thallium isotopes for tracing subduction zone inputs to the Mariana arc. Chem. Geol. 2013, 345, 139-149; DOI 10.1016/j.chemgeo.2013.03.003.

(2) Hettman, K.; Marks, M. A. W.; Kreissig, K.; Zack, T.; Wenzel, T.; Rehkämper, M.; Jacob, D. E.; Markl, G. The geochemistry of $\mathrm{Tl}$ and its isotopes during magmatic and hydrothermal processes: The peralkaline Ilimaussaq complex, southwest Greenland. Chem. Geol. 2014, 366, 1-13; DOI 10.1016/j.chemgeo.2013.12.004.

(3) Baker, R. G. A.; Rehkämper, M.; Hinkley, T. K.; Nielsen, S. G.; Toutain, J. P. Investigation of thallium fluxes from subaerial volcanism-Implications for the present and past mass balance of thallium in the oceans. Geochim. Cosmochim. Acta 2009, 73, 6340-6359; DOI 10.1016/j.gca.2009.07.014. 